\title{
Dielectric loss and extended voltage response measurements for low-voltage power cables used in nuclear power plant: potential methods for aging detection due to thermal stress
}

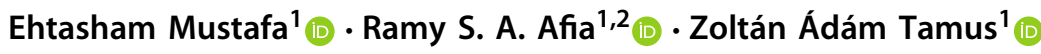

Received: 30 December 2019 / Accepted: 6 October 2020 / Published online: 29 October 2020

(c) The Author(s) 2020

\begin{abstract}
This paper discusses the effect of thermal stress on the electrical properties, conduction and polarization, of low-voltage CSPE/XLPE-based power cables used in a nuclear power plant. The cables were subjected to an accelerated thermal stress at $120^{\circ} \mathrm{C}$ for an equivalent service period of $20,40,60$ and 80 years. The capacitance, $\tan \delta$, resistivity at different frequencies and extended voltage response were the methods used for the investigation. A significant variation in the values of $\tan \delta$ at low frequency, i.e., at $100 \mathrm{~Hz}$, was observed. For the extended voltage response measurement, the decay voltage slope increased, showing the increase in the conduction particles inside the insulation material. While the decrease in return voltage slope showed that the slow polarization processes occurring at very low frequencies were decreased with aging. A strong correlation between the tan $\delta$ and decay voltage slope was also observed, which increased as the insulation aging increased. The results showed that the methods could be used for the in situ measurement of conduction and polarization phenomenon in the low-voltage cables, and hence helping in the assessment of the condition of cable insulation.
\end{abstract}

Keywords Low-voltage cables $\cdot$ Thermal aging $\cdot$ Conduction $\cdot$ Polarization $\cdot$ Tan $\delta \cdot$ Capacitance $\cdot$ Resistivity $\cdot$ EVR

\section{Introduction}

An important aspect for a nuclear power plant (NPP) life management about the long-term reliable operation is the condition monitoring (CM) of cable's insulation and jacket [1]. The NPP has round about 1000-2000 km of low-voltage (LV) power and instrumentation and control (I\&C) cables, and the integrity of these cables is of great importance to the normal operation generally, and in the case of a life extension of the NPP especially. Due to their location, these cables

Ehtasham Mustafa

mustafa.ehtasham@vet.bme.hu

Ramy S. A. Afia

ramysaad@h-eng.helwan.edu.eg

Zoltán Ádám Tamus

tamus.adam@vet.bme.hu

1 Department of Electric Power Engineering, Budapest University of Technology and Economics, 18 Egry József Street, Budapest 1111, Hungary

2 Department of Electrical Power and Machines Engineering, Helwan University, 1 Sheriff Street, Helwan, Cairo 11792, Egypt are exposed to humidity, radiation, vibration, chemical contact, mechanical bending and heating stresses, and hence are degraded over time. Therefore, the assessment of the condition, the process of aging and the degradation of the insulation of the cables are important. Taking into consideration the importance, a lot of work has been done in this regard, such as accelerated tests and types of tests to be undertaken [2-4].

As the insulation and jacket of LV cables are composed of polymer and it has been reported that the polymer material loses its functionality more due to the thermal stress than the radiation stress in the NPP environment. The thermal stress can be due to both self-heating (ohmic heating) and environmental temperature effect $[5,6]$ and can produce chemical and physical deterioration processes inside the material. In recent times, destructive methods have been used to determine the functionality of these cables, such as mechanical: elongation at break, indenter modulus $[7,8]$ and chemical: oxidation induction time, density, soluble fraction, infrared spectroscopy [9-17]. Due to the physicochemical changes, the primary purpose of the cable insulation (inner insulation and jacket), which is its electrical integrity, is affected by the perspective of polarization processes. Hence, the dielectric parameters and insulation characteristics are 
influenced. In the last few years, the methods used for the investigation of the effect of aging on the electrical properties are line resonance analysis (LIRA) [18], dielectric spectroscopy [19], time-domain reflectometry (TDR) and return voltage. Although these methods are nondestructive, the results reported by these methods are still not sufficient to state them as an effective online testing diagnostic tool. Besides, they also lack to report the conduction and the polarization processes which can be used to study the chemical changes happening inside the polymeric insulation due to thermal stress.

This paper has been focused to study the influence of thermal stress on the conduction and the polarization phenomenon in CSPE/XLPE insulation material used in the LV NPP power cable. The frequency-dependent dielectric parameters: capacitance, dissipation factor $(\tan \delta)$ and resistivity, were measured for a wide range of frequency to detect the insulation state. The method has been implemented as a diagnostics method for the medium voltage cables used in NPP [20], while time-domain extended voltage response (EVR) technique was used to investigate the slow polarization processes in the LV NPP cable and hence reflecting the aging information. The methods have the advantage of being nondestructive, and the results showed that all the parameters measured were very helpful in studying the degradation of the polymeric insulation and jacket. The aging markers obtained from the measurements are a practical step forward towards the implementation of these methods as nondestructive methods for the CM of the LV cables in the NPP. Therefore, they can be used in the future to predict the remaining useful life of the cable insulation material, as has been suggested by the light water reactor sustainability program nondestructive evaluation (NDE) report [21].

The paper has been organized as follows: the composition of the cable and characteristics, accelerated thermal aging, measurement of capacitance, $\tan \delta$, and resistivity, and EVR setup have been presented in Sect. 2. In Sects. 3 and 4, the results of the measurements and discussion have been presented, respectively. A correlation between $\tan \delta$ and EVR is established in Sect. 5, while the conclusion and discussion on future perspectives are presented in Sect. 6.

\section{Experimental Work}

\subsection{Specimens}

The LV power cable was composed of inner insulation as XLPE and the jacket CSPE (Hypalon®), Fig. 1. The cable consisted of a single tin-coated copper stranded conductor (diameter $=6.731 \mathrm{~mm}$ ). The thickness of the insulation was $1.143 \mathrm{~mm}$, while the jacket thickness was $0.762 \mathrm{~mm}$. A short length of the insulation was removed from the conductor, and

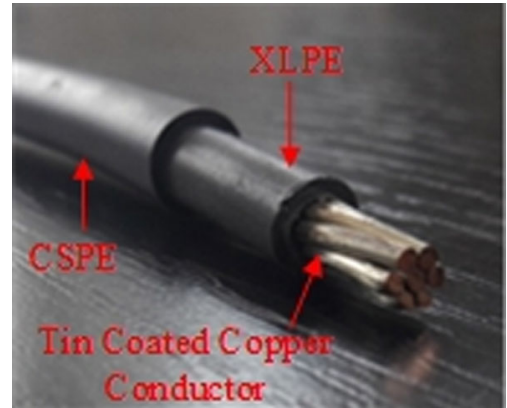

Fig. 1. Low-voltage power cable sample under investigation

a short length of the jacket was removed from the insulation as per the guidelines of the International Atomic Energy Agency (IAEA) [1].

\subsection{Thermal aging}

A half-meter long cable specimens were placed in an air circulated oven for the accelerated thermal aging at a temperature of $120^{\circ} \mathrm{C}$. The specimens were exposed to aging for a maximum period of $960 \mathrm{~h}$, and after every $240 \mathrm{~h}$, the cable specimens were withdrawn from the oven for the analysis. The aging hours were based on the Arrhenius relationship considering the activation energy of $1.23 \mathrm{eV}$, which were equivalent to $20,40,60$ and 80 years of service time at $60^{\circ} \mathrm{C}$ [22]. In order to realize the actual behavior of the cable during field environments, the aging was carried out on the whole cable without removing the jacket and the insulation from the conductor.

\subsection{Measurement of capacitance, $\tan \delta$ and resistivity}

The measurement of capacitance and resistivity represents the features of geometry and losses, respectively. Any degradation to the insulation geometry and resistance will result in the change of $\tan \delta$ [20]. Since in every polymer insulation, the polar groups interact in a different way with adjacent molecules due to nonidentical structures. This results in a different dipolar response at each frequency [23]. This makes the study of $\tan \delta$ at different frequencies suitable for the insulation diagnosis.

In this work, the measurement of capacitance, $\tan \delta$ and resistivity was performed using an impedance analyzer over the frequency range $20 \mathrm{~Hz}-500 \mathrm{kHz}$, input voltage of $5 V_{\text {rms }}$ at a temperature of $25^{\circ} \mathrm{C} \pm 2 \%$. The electrodes and the cable sample were kept in the Faraday cage to avoid any external noises pickup. A wire braid was placed on the outer surface of the cable for the measurement of the output signal, while the conductor was used for the application of the input signal. 
Fig. 2. Extended voltage response timing diagram

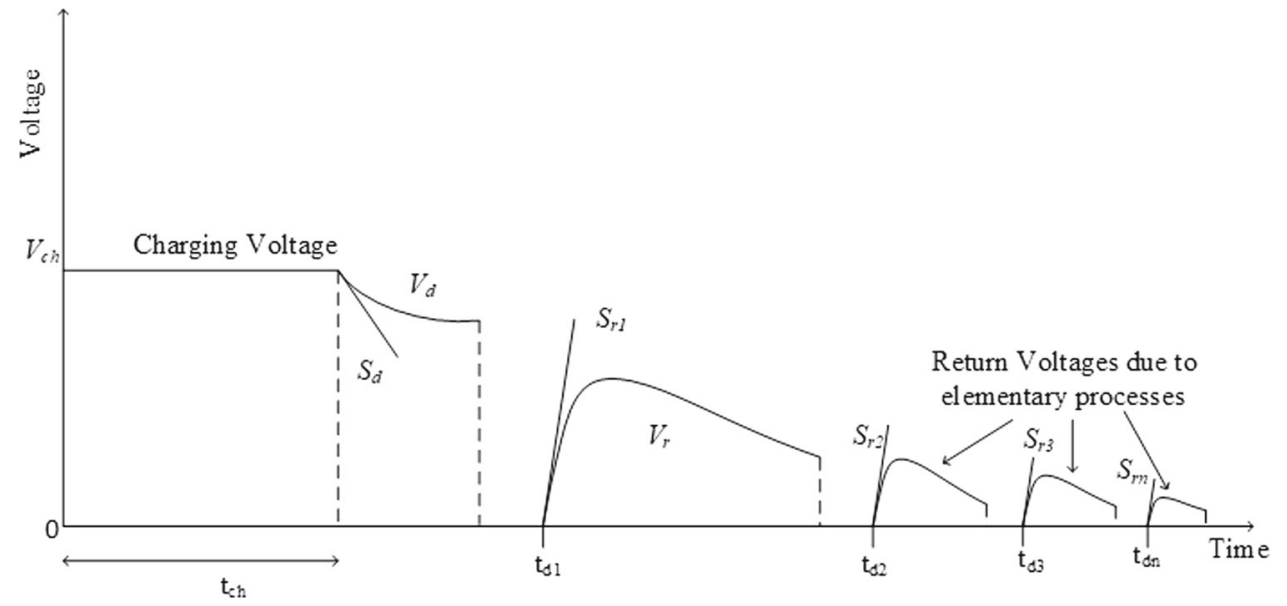

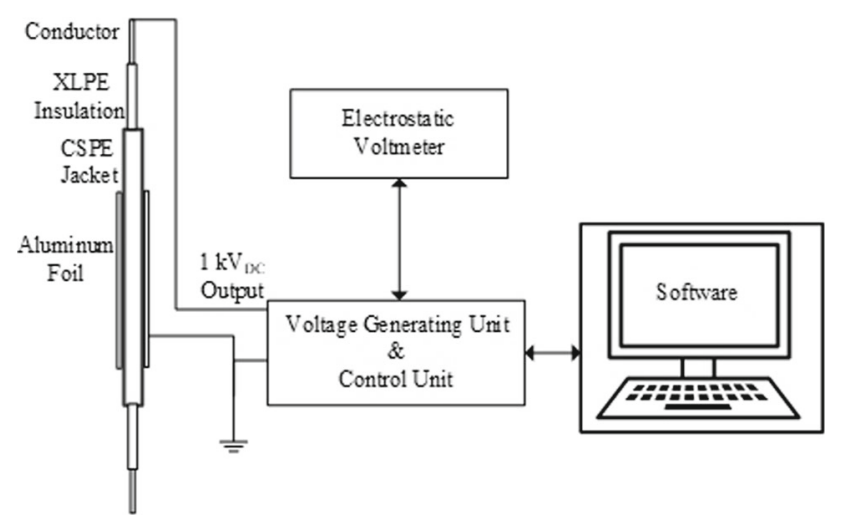

Fig. 3. Measurement setup of extended voltage response

\subsection{Extended voltage response}

EVR is an extended version of the voltage response method and has been developed in recent times. The method has successfully been implemented on LV cables used in the distribution system and high-voltage cables and transformer insulations [24-27]. The method is very helpful in studying the slow dielectric polarization effect in the insulation in the time domain. The EVR measurement of the cable samples was carried out by subjecting each cable sample to a DC voltage of $1000 \mathrm{~V}$ for $4000 \mathrm{~s}$, charging period. The voltage was applied between the conductor and the outer surface of the cable, Fig. 2. After the charging period, the cables were discharged for $2000 \mathrm{~s}$. Two voltage slopes: decay $S_{\mathrm{d}}$ and return $S_{\mathrm{r}}$ voltages, were measured by the device which was connected to the computer.

Figure 3 shows the setup of the EVR measurement. The $S_{\mathrm{d}}$ was measured after the disconnection of the supply voltage after the charging period, while the $S_{\mathrm{r}}$ was measured for 20 discharging times after short-circuiting. These discharging times gave a wide range of the slow polarization spectrum.
The decay and return voltage slopes were calculated according to the following relationships:

$S_{\mathrm{d}}=\left(V_{\mathrm{ch} / \epsilon_{o}}\right) \gamma$

$S_{\mathrm{r}}=\left(V_{c h} / \epsilon_{o}\right) \beta$

Equation 1 shows that the decay voltage is related to the specific conductivity $\gamma$ of the insulation, while Eq. 2 shows the relationship between the return voltage slope and the polarization conductivity $\beta$ of the insulation. The test temperature and humidity were $25^{\circ} \mathrm{C} \pm 2 \%$ and $25 \% \pm 2 \%$, respectively, for all the measurements. After the EVR measurements, the cable samples were discharged for five hours before the start of the next thermal cycle.

\section{Experimental results}

\subsection{Capacitance, $\tan \delta$ and resistivity of unaged and aged cable samples}

Figure 4 shows the capacitance of the unaged and aged cable samples. Irrespective of the aging, the capacitance of the cable increased as the frequency was shifted to the lower values. After the first thermal cycle, the capacitance increased while no significant change was observed after the second thermal cycle. But after the third thermal cycle, it increased again and then decreased after the fourth thermal cycle. The overall impact of aging on the capacitance was reflected as an increase in its values.

Figure 5 shows the $\tan \delta$ of the cable for the range of frequency under consideration. The $\tan \delta$ started from a higher value at high frequency and then moved to a minimum value with the decrease in the frequency. After reaching the minimum value at a certain frequency, it started to increase as the frequency was further lowered. This behavior was observed 


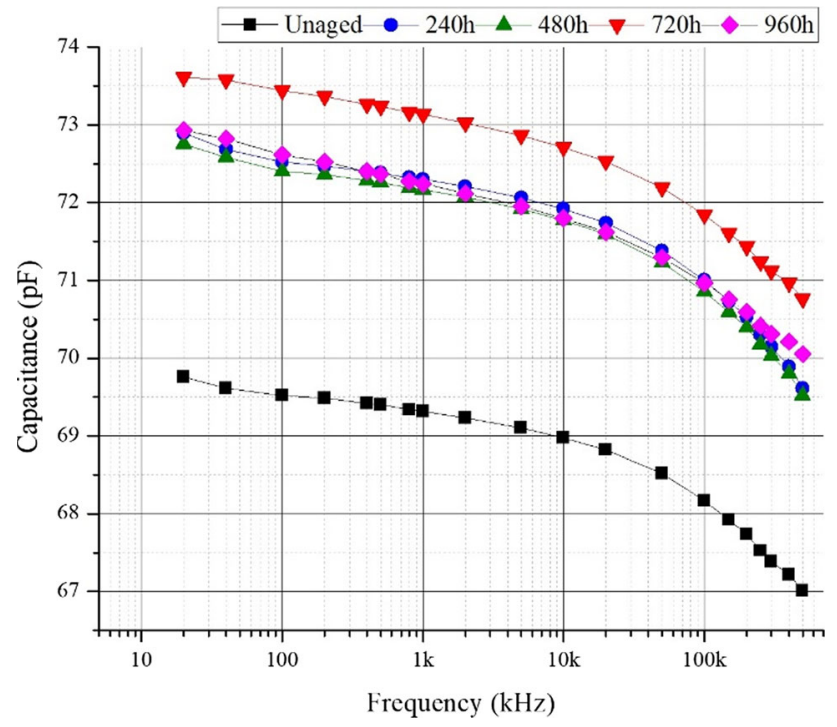

Fig. 4. Capacitance versus frequency for different aging time

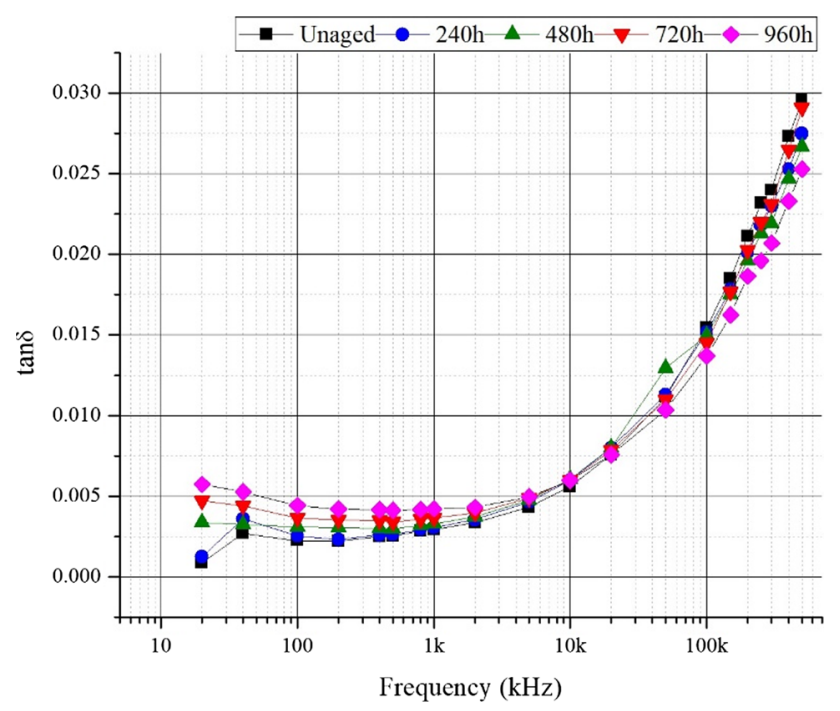

Fig. 5. $\tan \delta$ versus frequency for different aging time

for both the unaged and aged cable samples. The $\tan \delta$ showed an interesting behavior with the change of frequency and the aging. The $\tan \delta$ showed an increasing trend for a frequency range of $20 \mathrm{~Hz}-50 \mathrm{kHz}$; while between 100 and $500 \mathrm{kHz}$, the $\tan \delta$ values decreased after the first and the second thermal cycle. After, the third thermal cycle, a decrease in the values of the $\tan \delta$ was observed in a frequency range of 10 and $100 \mathrm{kHz}$, whereas at all other frequencies the values of $\tan \delta$ increased. After the fourth thermal cycle, the $\tan \delta$ decreased between 10 and $500 \mathrm{kHz}$; however, an increase was observed for the $20 \mathrm{~Hz}-5 \mathrm{kHz}$, low-frequency range. The overall effect of the aging on the $\tan \delta$ was shown as an increase in the values in the frequency range of $20 \mathrm{~Hz}$ to $5 \mathrm{kHz}$, but a decrease in the values between 10 and $500 \mathrm{kHz}$.
The resistivity of the unaged and aged cable is shown in Fig. 6a; with decrease in frequency, the resistivity increased unrelatedly of the aging. After the first thermal cycle, a decrease in resistivity was observed between $20 \mathrm{~Hz}$ and 150 $\mathrm{kHz}$, while it increased from $200 \mathrm{kHz}$ up to $500 \mathrm{kHz}$. Similarly, after the second thermal cycle, the resistivity decreased between $20 \mathrm{~Hz}$ and $10 \mathrm{kHz}$, but an increase in the values was observed between $20 \mathrm{kHz}$ and $500 \mathrm{kHz}$. A further decrease in the values of the resistivity was observed between $20 \mathrm{~Hz}-5$ $\mathrm{kHz}$ and $150-500 \mathrm{kHz}$ frequency ranges after the third thermal cycle, whereas an increase was detected between 10 and $100 \mathrm{kHz}$. After the fourth thermal cycle, between 10 and $500 \mathrm{kHz}$, the resistivity values increased while they decreased at all other frequencies. Figure $6 \mathrm{~b}$ refers to the change of resistivity with respect to unaged cable at selected frequencies, i.e., $100 \mathrm{~Hz}, 500 \mathrm{~Hz}, 100 \mathrm{kHz}$, and $500 \mathrm{kHz}$.

\subsection{EVR measurements}

The results of EVR measurements are shown in Fig. 7. The change in the values of $S_{\mathrm{d}}$ with the aging time is shown in Fig. 7a. An increase in the values of $S_{\mathrm{d}}$ was observed with each aging cycle, while the $S_{\mathrm{r}}$ for the different aging cycles is plotted against the discharging times on a logarithm scale in Fig. 7b. It was observed that with an increase in the aging period, the $S_{\mathrm{r}}$ values decreased.

\section{Discussion}

\subsection{Capacitance, $\tan \delta$ and resistivity}

In an insulating material, the dielectric losses can be categorized into three main components, conduction losses $\left(\tan \delta_{\mathrm{c}}\right)$, polarization losses $\left(\tan \delta_{\mathrm{p}}\right)$ and partial discharge losses $\left(\tan \delta_{\mathrm{PD}}\right)$, which can be shown as a summation of the total dissipation factor [28]:

$\tan \delta=\tan \delta_{\mathrm{c}}+\tan \delta_{\mathrm{p}}+\tan \delta_{\mathrm{PD}}$

At the low electric fields, the conduction and polarization losses are developing in contrast to partial discharge losses which are prominent in high electric fields. The measurements were carried under $5 \mathrm{~V}_{\mathrm{rms}}$ electric field, which makes the conduction and polarization losses more of our interest. The conduction losses are due to the transportation of free mobile charge carriers such as ions or electrons, while the polarization is a more complex phenomenon because of several elementary processes. The main polarization mechanisms occurring in the insulation material are electronic, ionic, dipolar, interfacial and hopping polarization. The electronic polarization is very fast and is effective up to optical frequency, while the interfacial and the hopping polariza- 
Fig. 6. a Resistivity versus frequency for different aging time, $\mathbf{b}$ change of resistivity with aging time (h) at $100 \mathrm{~Hz}$, $500 \mathrm{~Hz}, 100 \mathrm{kHz}$ and $500 \mathrm{kHz}$
Fig. 7. EVR measurement a $S_{\mathrm{d}}$ versus aging hours, b $S_{\mathrm{r}}$ versus discharging time for different aging time

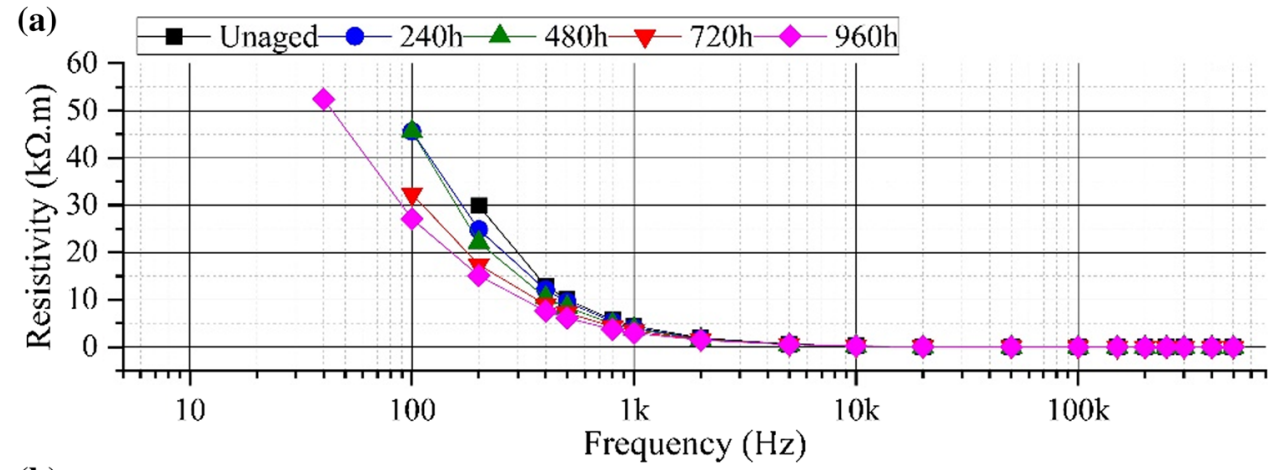

(1)
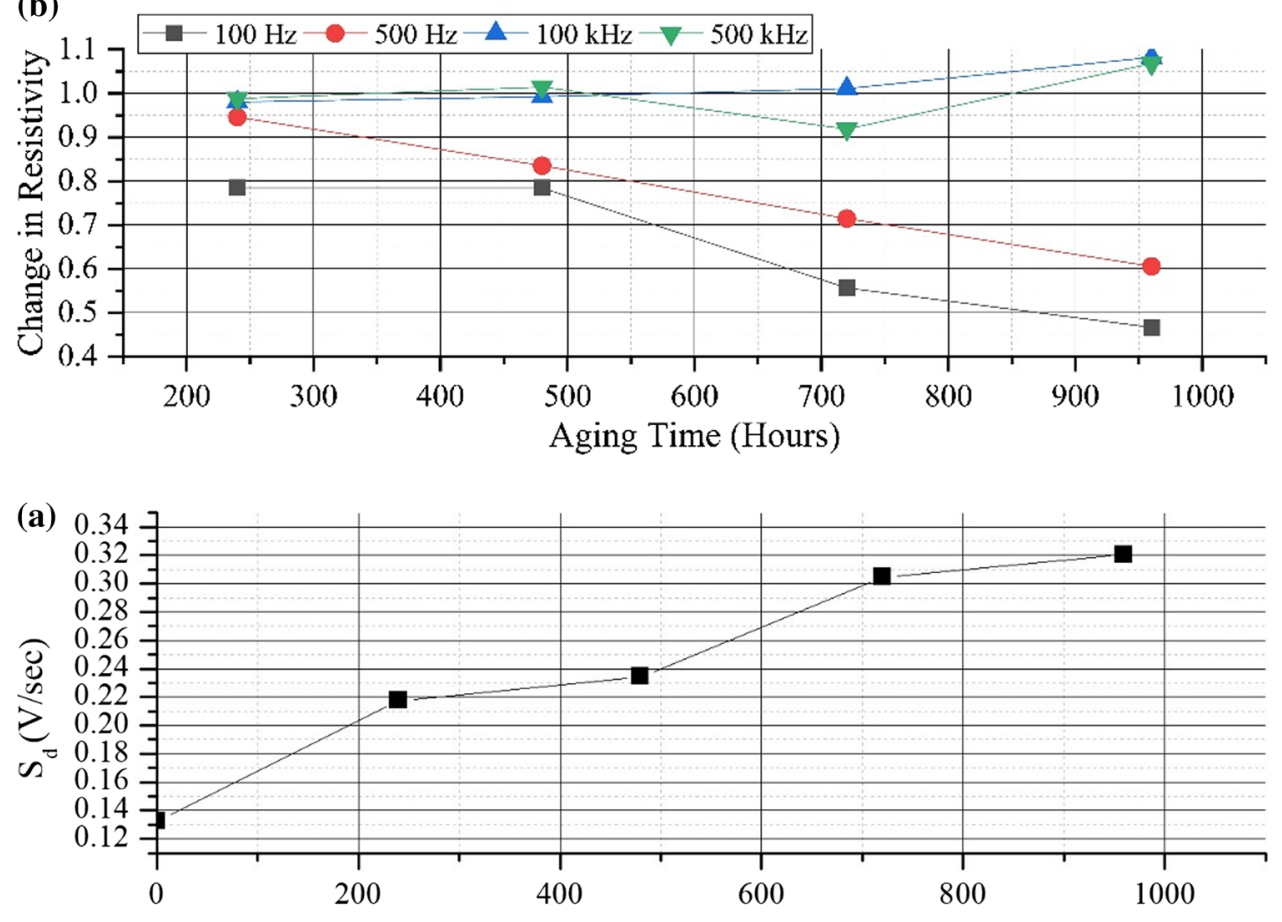

Aging Time (Hours)

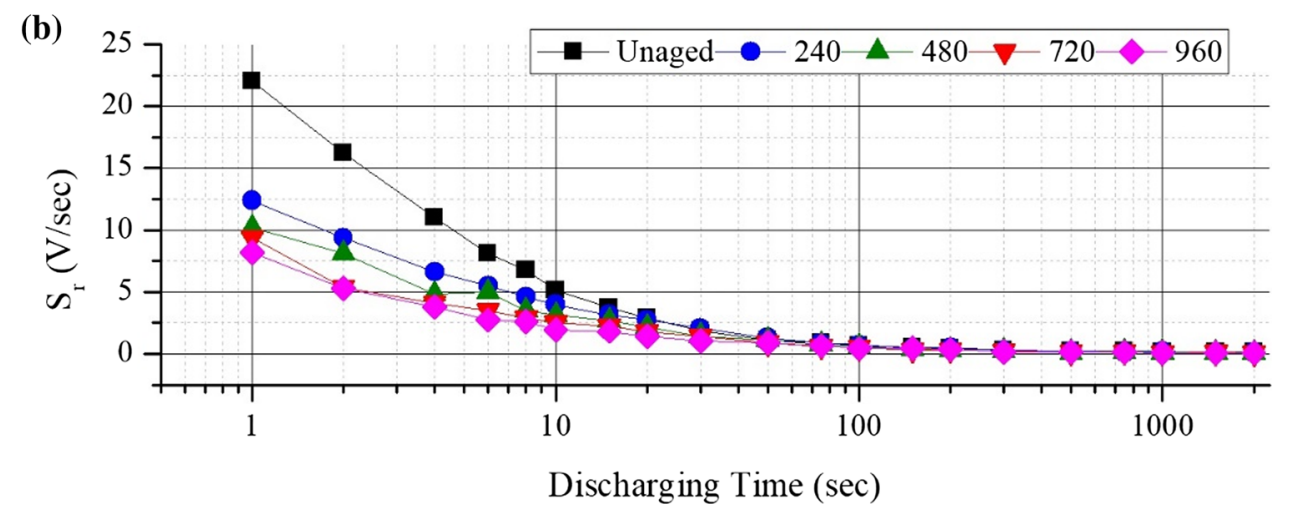

tions are considered very slow polarizations. The dipolar polarization occurs up to $\mathrm{MHz}$ and some $\mathrm{GHz}$, while ionic polarization takes place in the infrared region [29]. Since the frequency range under consideration is between $20 \mathrm{~Hz}$ and $1 \mathrm{MHz}$, the interfacial and dipolar polarization will be the subject of interest. Therefore, the $\tan \delta$ values will help in better understanding the conduction and the polarization losses relating to the inside structural changes of the material. Moreover, the capacitance has a strong relationship with the polarization phenomenon; hence, the variation in capacitance values helps in understanding the production of the dipolar species. 
The insulation material used in the cable in this study is XLPE, while the jacket material is CSPE. Both the materials are semicrystalline and are produced by the modification of the backbone of polyethylene [30, 31]. Chlorination and chlorosulfonation of polyethylene results in the formation of CSPE, while cross-linking the chains of polyethylene results in the formation of XLPE. Since each material is dielectric, any change in the material structure will affect the capacitance and the $\tan \delta$ properties. Furthermore, we have seen that the results of capacitance, $\tan \delta$ and resistivity have shown variation with different frequency range; thus, it is convenient to have the analysis into two blocks of the frequency range.

\section{(i) Frequency range: $20 \mathrm{~Hz}-50 \mathrm{kHz}$}

It was observed that the $\tan \delta$ values increased at a lowfrequency range: $20 \mathrm{~Hz}-5 \mathrm{kHz}$, for all thermal cycles. Also, the capacitance values increased until the third thermal cycle in the frequency range; this shows that due to thermal stress morphological changes have happened inside the polymer matrix. This has resulted in the generation of dipolar products which leads to the production of electric dipole rotation and hence an increase in the interfacial polarization losses, which is also evident by the decrease in the resistivity of the material in the lower-frequency range. In XLPE and CSPE due to the thermal stress, in the presence of oxygen, chain scission and cross-linking reactions along with oxidation reactions take place both in the amorphous and crystalline regions. The chain scission reaction results in the breakage of polymer backbones, resulting in the generation of alkyl radicals, which are free radicals. These radicals either react with oxygen forming peroxy radicals alongside the generation of more free radicals or they react with each other through crosslinking [30]. With the application of the external electric field, these chemical species respond to the field. The increase in the values of $\tan \delta$ could be attributed to the contribution of the alkyl and peroxy radicals, which are contributing to both interfacial and dipolar polarization losses.

The creation of new bonds because of more thermal stress has been depicted with a decrease in the values of capacitance after the fourth thermal cycle. Besides chain scission reaction, in polyethylene with more thermal stress the radicals cross-link with each other and they do not respond to the changing alternating field; hence resulting in the decrease in capacitance values. The further lowering of the values of resistivity and increasing values of $\tan \delta$ after the fourth thermal cycle depicts the presence of chemical species, generated due to the radicals which are increasing the interfacial and dipolar polarization losses. This is possible as with more thermal stress, the alkyl radicals along with peroxy radicals can result in a chain of reaction where new free radicals are generated besides other chemical species such as ketones and hydroperoxides. The hydroperoxides with the ability to decompose result in the formation of new free radicals, which may contribute to the conduction losses and hence to the overall value of $\tan \delta[30]$.

\section{(ii) Frequency range: $100-500 \mathrm{kHz}$}

The change in the values of $\tan \delta$ in the low-frequency range is more prominent as compared to the high-frequency range. Figure 8 shows the change of capacitance and $\tan \delta$ values with reference to unaged samples at four different frequencies: $100 \mathrm{~Hz}, 500 \mathrm{~Hz}, 100 \mathrm{kHz}$ and $500 \mathrm{kHz}$. The variation is higher at the lower frequencies in comparison with the higher frequencies, where the values have decreased with aging. It is possible that due to high thermal stress, the by-products created may have bound with the polyethylene end groups, this may have resulted in the decrease in small molecules, and hence, they do not respond to the high changing electric field and resulting in the decrease in $\tan \delta$ values [32].

Moreover, it was observed that the minimum value of $\tan \delta$ shifted from a lower frequency; $200 \mathrm{~Hz}$ to a higher frequency; $500 \mathrm{~Hz}$ with aging, Fig. 9, which is due to the production of dipolar particles and free radicals.

\subsection{EVR}

Whenever a DC voltage is applied to an insulating material, the charging current is more prominent as compared to the leakage and the absorption current. The charging current contains three components: the first one is related to the intrinsic conductivity and is independent of the polarization, the second one is related to the very fast polarization processes because of the delta function, while the third one is related to all polarization processes during the voltage application [29]. In the EVR, when the material is separated from the voltage source, the charges accumulated on the electrodes are discharged in the insulation material; this results in the generation of decay voltage. While the return voltage arises after the shortening period, this results in the discharging of the free charges and the polarization processes inside the material begin to regress. Hence, the decay voltage is related to the specific conductivity of the material, while the return voltage is related to the polarization conductivity of the material, as expressed in Eqs. 1 and 2.

From the results of EVR measurements, the $S_{\mathrm{d}}$ increased with the aging time, which shows that due to thermal aging conductive paths have been created because of the structural changes happening inside the polymer matrix, which allows the accumulated electrode charge particles to occupy these paths which are at the low energy level. This also shows that the insulation resistance has decreased with aging, which has 
Fig. 8. Variation of $\mathbf{a}$ capacitance and $\mathbf{b} \tan \delta$ with aging at $100 \mathrm{~Hz}, 500 \mathrm{~Hz}, 10 \mathrm{kHz}$ and $500 \mathrm{kHz}$. The variation is reported in relative value to that measured on an unaged sample
$-100 \mathrm{~Hz}-500 \mathrm{~Hz}-100 \mathrm{kHz}-500 \mathrm{kHz}$

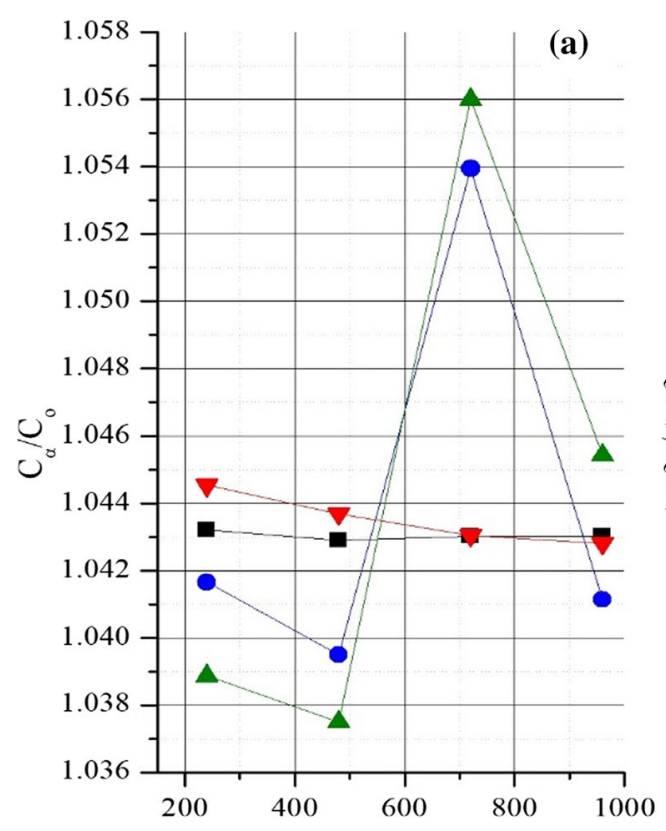

Aging Time (Hours)

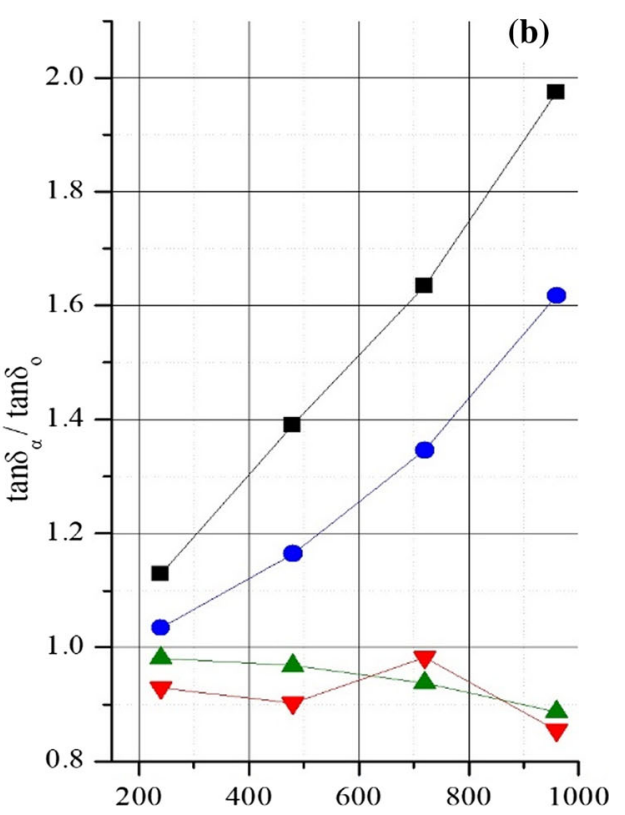

Aging Time (Hours)

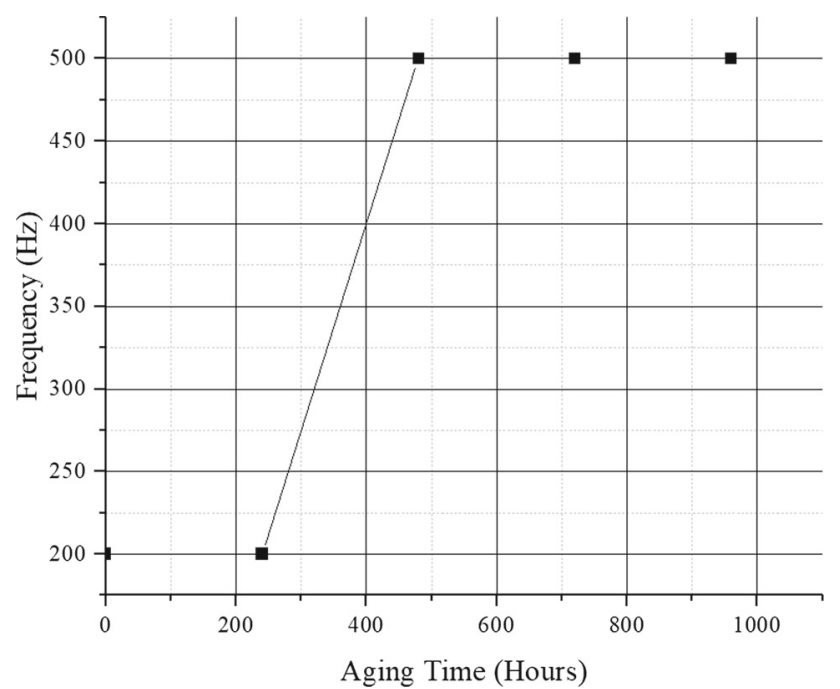

Fig. 9. Shifting of minimum value of $\tan \delta$ with aging

been observed for both CSPE and XLPE under thermal stress due to the separation of branch chains from the main chain resulting in the production of free radicals hence contributing to the leakage current [31-33].

Since the profile of $S_{\mathrm{r}}$ is developed due to the slow polarization processes which have high time constants or occur at very low frequencies, the decrease in the values of $S_{\mathrm{r}}$ with aging shows that the polarized particles, space charges, which have very high time constants and occur at very low frequencies, have decreased with aging, Fig. 10. Because CSPE and XLPE both are thermosets in nature, there is a phenomenon

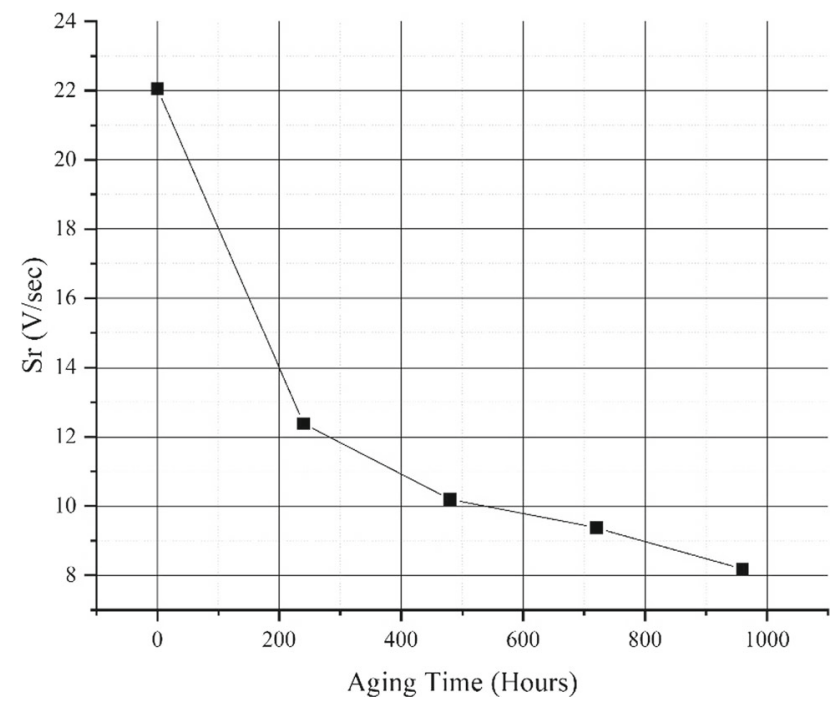

Fig. 10. $S_{\mathrm{r}}(V / \mathrm{sec})$ at $1-\sec v / \mathrm{s}$ aging time $(\mathrm{h})$

of cross-linking under the thermal stress which is associated with the type of materials as discussed in Sect. 4.1 [34]. The cross-linking is a three-dimensional network within the molecules and restricts the mobility of the charge transportation [35], making the molecules not to travel to the interface of the two insulation materials, i.e., CSPE and XLPE and which results in the decrease in space charge polarization; henceforth, a decrease in the values of $S_{\mathrm{r}}$ has been observed. It is interesting that in CSPE apart from cross-linking the phenomenon of dehydrochlorination happens under the thermal 
stress [36]. For the reason, the chlorine is separated from the main molecular chain of the polyethylene, this results in the decrease in dipoles, i.e., $\mathrm{C}-\mathrm{Cl}$ bonds, and consequently, dielectric relaxation is decreased [37].

\section{Correlation between $\tan \delta$ and $S_{d}$}

Figure 11 shows the correlation between the $S_{\mathrm{d}}$ and $\tan \delta$ for the CSPE/XLPE-based cable specimen. The $\tan \delta$ value has been taken at a low frequency of $100 \mathrm{~Hz}$. The experimental results are correlated by linear regression. The quality of the fitting is quantified by the correlation coefficient $R$, which is very high for the case. This implies that the $\tan \delta$, particularly at $100 \mathrm{~Hz}$ and $S_{\mathrm{d}}$, is strongly correlated with each other. Figure 12 shows a strong trend of $\tan \delta, S_{\mathrm{d}}$ with aging time, making them strong aging markers.

\section{Conclusion}

The effect on conduction and slow polarization charges in thermally aged CSPE/XLPE-based LV NPP power cables are studied in this paper. The $\tan \delta$ at low frequencies shows the sign of degradation of the cable due to chain scission reactions also the $S_{\mathrm{d}}$ values obtained by the EVR give a good aging marker. The resistivity of the material at low frequencies also decreased, while the lowering of the $S_{\mathrm{r}}$ values shows that the slow polarization processes decay over with the passage of time due to the phenomenon of crosslinking, which is associated with polyethylene. The shifting of the minimum value of the $\tan \delta$ towards higher frequency

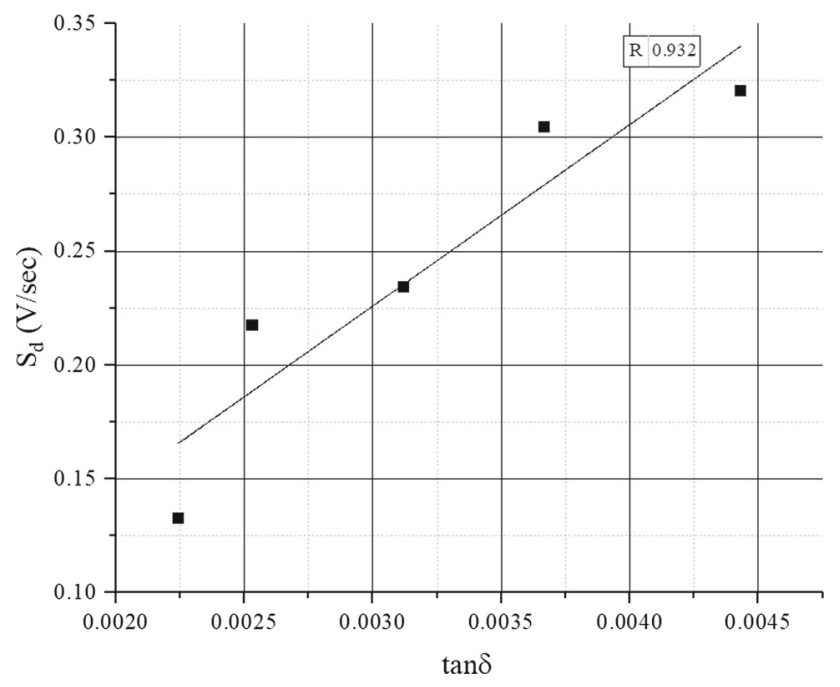

Fig. 11. Correlation between $S_{\mathrm{d}}$ and $\tan \delta$ at $100 \mathrm{~Hz}$

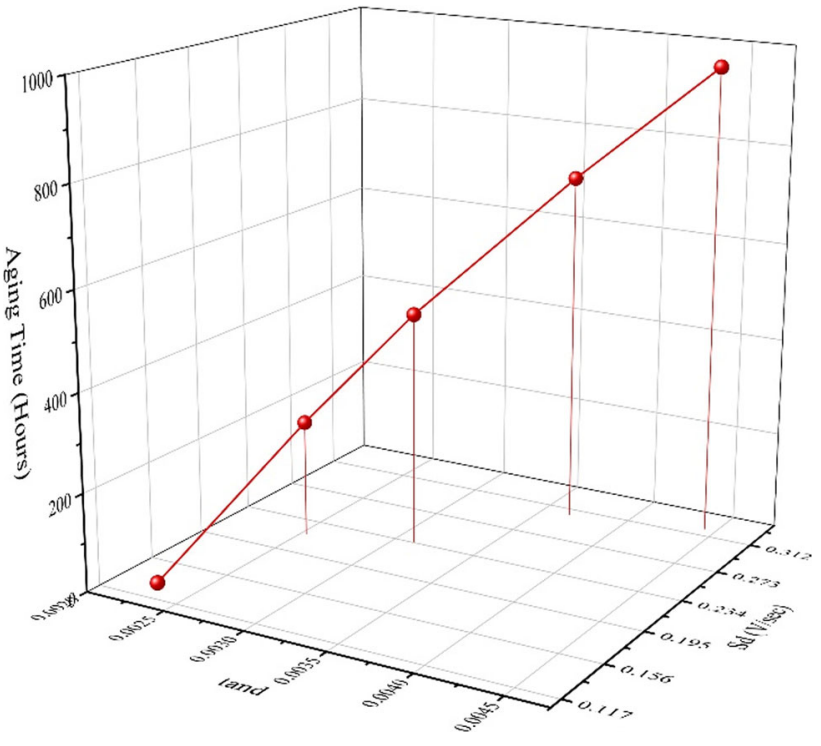

Fig. 12. Trending of $\tan \delta$ and $S_{\mathrm{d}}$ with aging time in hours

with aging shows the increase in interfacial and dipolar polarization losses besides the contribution of conduction losses due to the presence of free radicals. A strong correlation between the $\tan \delta$ at $100 \mathrm{~Hz}, S_{\mathrm{d}}$ and aging times has been observed. These results show that the electrical properties discussed in this paper can be used to assess the condition of the cable. The techniques are nondestructive and show the potential to be applied in the NPP for the online CM of the LV cables simply and effectively. The techniques also have the feature of being independent of the geometry of the cable. Further work is needed to be done to set the threshold values for the properties, which would help to determine the state of the cable and then predict the remaining life of it.

Acknowledgement This research work has been carried out under Project No. 123672 with the support provided from the National Research, Development and Innovation Fund of Hungary, financed under the KNN_16 funding scheme.

Funding Open access funding provided by Budapest University of Technology and Economics.

Open Access This article is licensed under a Creative Commons Attribution 4.0 International License, which permits use, sharing, adaptation, distribution and reproduction in any medium or format, as long as you give appropriate credit to the original author(s) and the source, provide a link to the Creative Commons licence, and indicate if changes were made. The images or other third party material in this article are included in the article's Creative Commons licence, unless indicated otherwise in a credit line to the material. If material is not included in the article's Creative Commons licence and your intended use is not permitted by statutory regulation or exceeds the permitted use, you will need to obtain permission directly from the copyright holder. To view a copy of this licence, visit http://creativecomm ons.org/licenses/by/4.0/. 


\section{References}

1. International Atomic Energy Agency (2017) Benchmark analysis for condition monitoring test techniques of aged low voltage cables in nuclear power plants. IAEA-TECDOC-1825, Vienna, Austria

2. Agarwal VK, Banford HM, Bernstein BS et al (1995) The mysteries of multifactor ageing. IEEE Electr Insul Mag 11:37-43. https://doi. org/10.1109/57.387831

3. Mustafa E, Afia RSA, Tamus ZÁ (2019) Condition monitoring uncertainties and thermal - radiation multistress accelerated aging tests for nuclear power plant cables: A review. Period Polytech Electr Eng Comput Sci. https://doi.org/10.3311/ppee.14038

4. Liu S, Fifield LS, Bowler N (2019) Aging mechanisms and nondestructive aging indicator of filled cross-linked polyethylene (XLPE) exposed to simultaneous thermal and gamma radiation. Miner Met Mater Ser. https://doi.org/10.1007/978-3-030-04639-2_82

5. Blocker E, Smith S, Philpot L, Conley J (1996) Aging management guideline for commercial nuclear power plants - tanks and pools. Report, Albuquerque, New Mexico (https://digital.library. unt.edu/ark:/67531/metadc669628/. Accessed 26 Oct 2020), University of North Texas Libraries, UNT Digital Library, crediting UNT Libraries Government Documents Department. https:// digital.library.unt.edu

6. Gazdzinski RF, Denny WM, Toman GJ, Butwin RT (1996) Aging management guideline for commercial nuclear power plants. Electrical cable and terminations. California, USA

7. International Atomic Energy Agency (2000) Assessment and management of ageing of major nuclear power plant components important to safety: in-containment instrumentation and control cables, vol II, IAEA-TECDOC-1188, Vienna, Austria

8. IAEA (1997) Pilot study on the management of ageing of instrumentation and control cables. Results of a co-ordinated research programme 1993-1995, vol II, IAEA-TECDOC-932., Vienna, Austria.

9. Bartoníček B, Hnát V, Plaček V (1998) Life-assessment technique for nuclear power plant cables. Radiat Phys Chem 52:639-642. https://doi.org/10.1016/S0969-806X(98)00172-8

10. Anandakumaran K, Seidl W, Castaldo PV (1999) Condition assessment of cable insulation systems in operating nuclear power plants. IEEE Trans Dielectr Electr Insul 6:376-384. https://doi.org/10.11 09/94.775626

11. Mason LR, Doyle TE, Reynolds AB (1993) Oxidation induction time correlations with radiation dose and antioxidant concentration in EPR and XLPE polymers. J Appl Polym Sci 50:1493-1500. https://doi.org/10.1002/app.1993.070500902

12. Gillen KT, Assink RA, Bernstein R (2004) Condition monitoring approaches applied to a polychloroprene cable jacketing material. Polym Degrad Stab 84:419-431. https://doi.org/10.1016/j. polymdegradstab.2004.01.018

13. Seguchi T, Tamura K, Ohshima T et al (2011) Degradation mechanisms of cable insulation materials during radiation-thermal ageing in radiation environment. Radiat Phys Chem 80:268-273. https:// doi.org/10.1016/j.radphyschem.2010.07.045

14. Gillen KT, Celina M, Clough RL (1999) Density measurements as a condition monitoring approach for following the aging of nuclear power plant cable materials. Radiat Phys Chem 56:429-447. https://doi.org/10.1016/S0969-806X(99)00333-3

15. Gasa JV, Liu Z, Shaw MT (2005) Relationship between density and elongation-at-break of naturally and artificially aged cable materials used in nuclear power plants. Polym Degrad Stab 87:77-85. https://doi.org/10.1016/j.polymdegradstab.2004.07.009

16. Gillen KT, Bernstein R, Clough RL, Celina M (2006) Lifetime predictions for semi-crystalline cable insulation materials: I. Mechanical properties and oxygen consumption measurements on
EPR materials. Polym Degrad Stab 91:2146-2156. https://doi.org/ 10.1016/j.polymdegradstab.2006.01.009

17. Clough RL, Gillen KT (1981) Radiation-thermal degradation of PE and PVC: Mechanism of synergism and dose rate effects. Radiat Phys Chem 18:661-669. https://doi.org/10.1016/0146-5724(81)9 0189-8

18. Ekelund M, Fantoni PF, Gedde UW (2011) Thermal ageing assessment of EPDM-chlorosulfonated polyethylene insulated cables using line resonance analysis (LIRA). Polym Test 30:86-93. https://doi.org/10.1016/j.polymertesting.2010.11.003

19. Verardi L, Fabiani D, Montanari GC (2014) Electrical aging markers for EPR-based low-voltage cable insulation wiring of nuclear power plants. Radiat Phys Chem 94:166-170. https://doi.org/10.1 016/j.radphyschem.2013.05.038

20. Podkoritnik S, Jansa M, Manojlovic S (2016) Diagnostics and lifecycle assessment of medium-voltage cables in nuclear power plants during regular overhaul process. J Nuclear Eng Radiat Sci. https:// doi.org/10.1115/1.4032782

21. Bowler N, Liu S (2015) Aging mechanisms and monitoring of cable polymers. Int J Prog Heal Manag 6:1-12

22. Pirc M, Avsec J, KorošinNČ, Štangar UL, Korošec RC (2018) Cable aging monitoring with differential scanning calorimetry (DSC) in nuclear power plants. Trans FAMENA; 42: 87-98. https:// doi.org/10.21278/TOF.42Si108

23. Morsalin S, Phung TB, Danikas M, Mawad D (2019) Diagnostic challenges in dielectric loss assessment and interpretation: a review. IET Sci Meas Technol. https://doi.org/10.1049/iet-smt.2018.5597

24. Mustafa E, Afia RSA, Tamus ÁZ (2018) A review of methods and associated models used in return voltage measurement. In: 2018 Int Conf Diagn Electr Eng, Diagnostika 2018. Czech Republic, Pilsen, pp 69-72

25. Tamus ZÁ, Csányi GM, Szirmai Á, Nagy A (2016) Insulation diagnostics of high voltage equipment by dielectric measurements-Hungarian research and experience. In: 2016 int sci symp-electr power eng. Varna, Bulgaria, pp 7-13

26. Csányi GM, Tamus ZÁ (2017) Investigation of dielectric properties of mixed PILC and XLPE cable insulation by the extended Voltage Response Method. In: 2017 6th int Youth Conf Energy, IYCE 2017. Budapest, Hungary, pp 1-4. https://doi.org/10.1109/IYCE.2017.8 003702

27. Tamus ÁZ, Szirmai Á, Nemeth B (2015) Comparison of voltage response and return voltage measurements of a transformer insulation model. In: The 19th int symp high volt eng. Pilsen, Czech Republic

28. Farahani M, Borsi H, Gockenbach E (2007) Study of capacitance and dissipation factor tip-up to evaluate the condition of insulating systems for high voltage rotating machines. Electr Eng 89:263-270. https://doi.org/10.1007/s00202-006-0011-9

29. Zaengl WS (2003) Dielectric spectroscopy in time and frequency domain for HV power equipment. I. Theoretical considerations. IEEE Electr Insul Mag 19:5-19. https://doi.org/10.1109/MEI.200 3.1238713

30. Mosleh A, Chang Y-S (2019) Physics-based probabilistic model of the effects of ionizing radiation on polymeric insulators of electric cables used in nuclear power plants. California, USA

31. Lee JH, Kang MK, Jeon JS et al (2014) A study on the properties of CSPE according to accelerated thermal aging years. J Electr Eng Technol 9:643-648. https://doi.org/10.5370/JEET.2014.9.2.643

32. He D, Gu J, Wang W et al (2017) Research on mechanical and dielectric properties of XLPE cable under accelerated electricalthermal aging. Polym Adv Technol 28:1020-1029. https://doi.org/ 10.1002/pat.3901

33. Shin Y-D (2018) Phase degree of response voltage and current versus excitation voltage of the accelerated thermally aged CSPE. Trans Electr Electron Mater 19:112-117. https://doi.org/10.1007/ s42341-018-0020-1 
34. Anadakumaran K, Stonkus DJ (1992) Assessment of oxidative thermal degradation of crosslinked polyethylene and ethylene propylene rubber cable insulation. Poly Eng Sci 32:1386-1393. https://doi.org/10.1002/pen.760321808

35. Boukezzi L, Rondot S, Jbara O, Boubakeur A (2017) A timeresolved current method and TSC under vacuum conditions of SEM: trapping and detrapping processes in thermal aged XLPE insulation cables. Nucl Instruments Methods Phys Res Sect B Beam Interact with Mater Atoms 394:126-133. https://doi.org/10.1016/ j.nimb.2017.01.011

36. Chailan JF, Boiteux G, Chauchard J et al (1995) Effects of thermal degradation on the viscoelastic and dielectric properties of chlorosulfonated polyethylene (CSPE) compounds. Polym Degrad Stab 48:61-65. https://doi.org/10.1016/0141-3910(95)00018-H
37. Mustafa E, Tamus ÁZ, Afia RSA (2019) Thermal degradation and condition monitoring of low voltage power cables in nuclear power industry. IFIP Adv Inf Commun Technol 553:405-413. https://doi. org/10.1007/978-3-030-17771-335

Publisher's Note Springer Nature remains neutral with regard to jurisdictional claims in published maps and institutional affiliations. 